\title{
The Role of Education on Disaster Preparedness: Case Study of 2012 Indian Ocean Earthquakes on Thailand's Andaman Coast
}

\author{
Raya Muttarak $^{1}$ and Wiraporn Pothisiri ${ }^{2}$
}

\begin{abstract}
In this paper we investigate how well residents of the Andaman coast in Phang Nga province, Thailand, are prepared for earthquakes and tsunami. It is hypothesized that formal education can promote disaster preparedness because education enhances individual cognitive and learning skills, as well as access to information. A survey was conducted of 557 households in the areas that received tsunami warnings following the Indian Ocean earthquakes on 11 April 2012. Interviews were carried out during the period of numerous aftershocks, which put residents in the region on high alert. The respondents were asked what emergency preparedness measures they had taken following the 11 April earthquakes. Using the partial proportional odds model, the paper investigates determinants of personal disaster preparedness measured as the number of preparedness actions taken. Controlling for village effects, we find that formal education, measured at the individual, household, and community levels, has a positive relationship with taking preparedness measures. For the survey group without past disaster experience, the education level of household members is positively related to disaster preparedness. The findings also show that disaster-related training is most effective for individuals with high educational attainment. Furthermore, living in a community with a higher proportion of women who have at least a secondary education increases the likelihood of disaster preparedness. In conclusion, we found that formal education can increase disaster preparedness and reduce vulnerability to natural hazards.
\end{abstract}

Key Words: disaster preparedness; earthquake; education; partial proportional odds model; Thailand; tsunami

\section{INTRODUCTION}

Although it remains impossible to predict when and where an earthquake will occur, the impacts of earthquake disasters can be reduced by taking a variety of personal safety measures (Turner et al. 1986, Lehman and Taylor 1987, Ramirez and Peek-Asa 2005). Likewise, catastrophes from a tsunami, a massive wave caused by undersea earthquakes, can be mitigated or avoided through effective warning systems. Indeed, the catastrophic loss of the Indian Ocean Tsunami of December 2004 was largely due to the absence of warning systems, lack of knowledge, and lack of preparedness among the populations at risk (Rachmalia et al. 2011).In contrast, in Japan's Tohoku earthquake on 11 March 2011, the effectiveness of local emergency warning systems and disaster preparedness among Japanese citizens saved many lives, despite the short time between the quake and the tsunami. These examples illustrate that personal disaster preparedness is critical to mitigate disaster impacts.

Being prepared for a major disaster is the most effective way to minimize the damage suffered by the affected population (Banerjee and Gillespie 1994). Emergency management officials and disaster planners recognize that for the first 72 hours after an earthquake or other disaster strikes, individuals and families should be prepared for self-sufficiency because services and supplies can be disrupted and emergency assistance might not be immediately available (Russell et al. 1995, Basolo et al. 2009). Preparedness is also associated with successful evacuations during a hurricane (Howell and Bonner
2005, Dash and Gladwin 2007) and improvements in individuals' resilience in coping with trauma (Bravo et al. 1990). Accordingly, the U.S. government has directed resources to improve individual emergency preparedness for both natural and man-made disasters (Eisenman et al. 2006).

Using the Indian Ocean earthquakes on 11 April 2012 as a case study, this paper investigates determinants of emergency disaster preparedness among residents living along the Andaman coast in Phang Nga province, Thailand. The 11 April earthquake not only set off tsunami warnings, but triggered a series of minor secondary earthquakes. The survey was conducted immediately after the Indian Ocean earthquakes and during and just after the period of the minor earthquakes, allowing us to observe disaster preparedness in the moment when that preparedness was being tested by events. We analyze preparedness actions for both the tsunami and earthquakes following the 11 April quakes. In particular, we investigate the association between educational attainment and disaster preparedness, taking into account relevant demographic, socioeconomic, and community characteristics that could influence preparedness actions. We examine how disaster preparedness varies by education at the individual, household, and community levels, and how education interacts with other characteristics in shaping preparedness behaviors. Moreover, given that people in a community interact and exchange information, we argue that living in a community with high average level of education is beneficial in improving preparedness levels.

\footnotetext{
${ }^{1}$ Wittgenstein Centre for Demography and Global Human Capital (IIASA, VID/ÖAW and WU), International Institute for Applied Systems Analysis, ${ }^{2}$ College of Population Studies, Chulalongkorn University
} 
This research adds to the literature on disaster preparedness and vulnerability in three ways. First, there have been few studies that focus on the relationship between educational attainment and disaster preparedness, and those that exist do not consider in depth how education can influence preparedness. In this paper we extend beyond the current literature by exploring plausible explanations how formal education can influence preparedness actions. Second, while most studies investigate the influence of individual or household-level education on disaster preparedness, we also consider the influence of community-level education and demographic factors. Third, scientific studies on disaster preparedness have been predominantly conducted in the U.S. There are very few studies on other countries, especially developing countries (Mishra and Suar 2007, Mishra et al. 2010, Ferdinand et al. 2012). We provide new empirical evidence on Thailand, where disaster preparedness has not yet been investigated.

\section{LITERATURE REVIEW AND HYPOTHESES}

Preparedness actions are influenced by a broad range of factors. Risk perception is strongly associated with disaster preparedness because individuals must perceive a risk to be motivated to initiate preparedness actions (Sattler et al. 2000, Miceli et al. 2008). An individual's previous experience with a hazardous event can heighten perception of risk and promote preparedness actions (Russell et al. 1995, Lindell and Perry 2000, Tekeli-Yeşil et al. 2010). Other factors that influence preparedness behaviors vary considerably with socioeconomic and demographic characteristics. Individuals of different social groups receive and evaluate risk information differently and have unequal resources to carry out preparedness measures. For instance, there is evidence that women and men differ in the types of preparedness activities they take. Although women are more likely to prepare their families for disaster than men, they are less represented in formal emergency planning organizations (Fothergill 1996). Preparedness increases with age (Sattler et al. 2000, Mishra and Suar 2005), but the very old are less likely to engage in preparation (Heller et al. 2005). In addition to education, socioeconomic factors including income, home ownership, and length of residence in the same location are also positively associated with disaster preparedness (Lindell and Perry 2000, Eisenman et al. 2006, Reininger et al. 2013).

Although many of the factors associated with disaster preparedness, such as age, sex, and race are ascribed characteristics that are determined by nature, characteristics such as income and education are qualities that are dependent on individual initiative and can be achieved over the life course. Because income and education are positively associated with disaster preparedness (Russell et al. 1995, Liu et al. 1996, Lindell and Perry 2000, Bourque et al. 2012), improving a person's socioeconomic level could directly or indirectly increase preparedness activities. We argue that education in particular is a key tool to promote disaster preparedness because highly educated individuals have better economic resources to undertake preparedness actions, and because education may influence cognitive elements and shape how individuals perceive and assess risks, and how they process risk-minimizing information (Menard et al. 2011).

Because preparedness action is closely related to how individuals perceive and act on risk information (Tierney et al. 2001), educated individuals might have more awareness of risks because they are likely to have greater access to information sources and be better able to evaluate the risk information (Jamison and Moock 1984, Rogers 1995, Asfaw and Admassie 2004). There is also evidence that education increases the acquisition of general knowledge that could influence values, priorities, capacity to plan for the future, and ability to appropriately allocate available resources (Thomas et al. 1991, Glewwe 1999, Burchi 2010). The knowledge and competence gained through education thus could be useful when a disaster strikes. This leads to the following hypotheses:

- H1: Education has a positive effect on disaster preparedness by improving income level, which is positively associated with preparedness.

- H2: Education has a positive direct effect on disaster preparedness because education enhances cognitive and risk evaluation skills.

Empirical evidence on the relationship between educational level and preparedness behaviors, however, has not been adequately established. Although some studies find that higher educational attainment enhances disaster preparedness (Edwards 1993, Norris et al. 1999, Murphy et al. 2009, Baker 2011, Menard et al. 2011), numerous other studies report no association between the two factors (Jackson 1981, Faupel et al. 1992, Siegel et al. 2003, Heller et al. 2005, Spittal et al. 2008, Kim and Kang 2010). Generally, education is treated as a control variable and emphasis is not put on understanding how education may influence preparedness behaviors. An exception is the recent study by Menard et al. (2011) that explicitly focuses on establishing the relationship between having a postsecondary degree and disaster preparedness. The study reported that individuals with a college degree are more likely to have an emergency plan and know where to get additional information. Going to college in the U.S. not only increases overall education, but exposes individuals to university emergency systems. Overall higher education and direct experience with an existing emergency system may influence how individuals process risk-minimizing information. Although Menard's study provides evidence on the influence of higher education on disaster preparedness, in the absence of multivariate analysis, it fails to consider confounding factors that can influence both education and preparedness. We fill this gap using multivariate models. 
Apart from formal schooling, there is evidence that disaster education interventions can be influential in raising awareness and knowledge of disasters, which in turn can enhance disaster preparedness actions (Faupel and Styles 1993, Tanaka 2005, Page et al. 2008). The link between formal schooling and disaster education interventions has been recognized and disaster-related education has been promoted by some international agencies as a key approach to build disasterresilient societies (UNISDR 2007, Selby and Kagawa 2012). Nevertheless, there are few empirical studies that consider the interplay between formal education and disaster education in shaping preparedness behaviors. Arguing that formal education can enhance learning skills, the hypothesis formulated here is as follows:

- H3: Disaster-related education increases disaster preparedness and the increase is even greater among highly educated individuals.

Because the majority of studies on disaster preparedness were predominantly carried out in the U.S. and focus on disaster preparedness for hurricanes, the identified associations between various characteristics and disaster preparedness may not apply to all types of disaster and geographical contexts (Kohn et al. 2012). In this paper we provide new empirical evidence on preparedness for earthquakes in Thailand.

\section{CASE STUDY OF 2012 INDIAN OCEAN EARTHQUAKES}

\section{Indian Ocean earthquakes}

We use the 2012 Indian Ocean earthquakes as a case study of personal emergency preparedness. Earthquakes are rare in Thailand. The country has experienced midsized earthquakes (M5.0 - 5.9) only eight times over the past 40 years (CICC 2012). As a result, preparedness for earthquakes has not been given a priority either at the national or individual level. The 2012 Indian Ocean earthquakes were followed by tsunami warnings and numerous other quakes. The earthquakes consequently put people in the region on high alert and may have triggered preparedness actions among the residents.

On 11 April 2012 at 15:38 local time, a powerful magnitude 8.6 undersea earthquake struck $434 \mathrm{~km}$ southwest of the Indonesian province of Banda Aceh in northern Sumatra. It was followed by another major shock (M8.2) at 17:43 local time $200 \mathrm{~km}$ to the south, as well as numerous aftershocks (USGS 2012). The Pacific Tsunami Warning Center issued a tsunami watch for countries all along the Indian Ocean rim, from Australia and India to far off Africa. In Thailand, the Department of the Disaster Prevention and Mitigation (DDPM) issued an urgent tsunami warning and evacuation order for people living on the Andaman coast of six southern provinces, the same region that had been hit by the 2004 Indian Ocean Tsunami. Fortunately, a devastating tsunami did not occur because both the initial earthquake and the M8.2 aftershock were a slip-strike earthquake whereby two tectonic plates, Indian and Australian plates, slid against one another horizontally and this lateral movement did not lead to a vertical displacement of water. The tsunami warnings were then lifted several hours later (BBC 2012).

Although a tsunami did not occur, the quakes sparked fear among local residents and tourists, especially in the areas damaged by the 2004 tsunami. This panic was exacerbated by the earthquake of 4.3 magnitude, which struck Phuket with its epicenter at Thalang district five days later, on 16 April 2012, at 16:44 local time. This was followed by a series of more than 26 aftershocks, occurring through 22 April 2012. The Phuket earthquakes might have been triggered by the Indonesian earthquake, as a recent study reports a significant increase in the occurrence of sizable quakes in the six days following 11 April (Pollitz et al. 2012). The Indonesian and the Phuket earthquakes put people living near the southern Andaman coast on high alert because of fear of the tremors and the threat of a repeat of the 2004 tsunami.

\section{DATA AND METHODS}

\section{Study area}

Phang Nga province was chosen for our study because the province suffered the greatest human loss and massive economic impact as a result of the 2004 tsunami. Of the six Thai provinces affected by the tsunami (Nidhiprabha 2010), with a coastline of $240 \mathrm{~km}$, Phang Nga alone experienced 5880 lives lost, accounting for $72 \%$ of the total deaths and missing persons in Thailand. Takua Pa District, a popular area for tourists because of its numerous beach resorts, was the most severely hit area in the 2004 disaster, with run-up heights varying between 5 to $10 \mathrm{~m}$ (FAO 2005, Römer et al. 2012). Inundation distances reached as far as two kilometers inland in some areas, causing widespread devastation (Thanawood et al. 2006).

Given the large-scale impacts from the 2004 event, Phang Nga residents might be expected to improve personal disaster preparedness initiatives. In this study, we assess disaster preparedness in the areas that were issued tsunami warnings on 11 April 2012 by the DDPM. Nine villages were randomly selected as interview sites. These villages varied considerably in terms of population numbers and level of disaster preparedness (see Fig. 1).

\section{Data sources}

The analysis is based on two data sources. The data for personal preparedness were obtained from a survey of households located in tsunami high-risk areas in Phang Nga province (see Fig. 1) conducted by the College of Population Studies, Chulalongkorn University between 17 April - 13 May 2012. The survey consisted of face-to-face interviews carried out in the Thai language by trained interview staff and local researchers. For each village, $30 \%$ of the households were 
Fig. 1. Map of sampled nine villages in Phang Nga province and percentage of respondents undertaking preparedness actions in a village (size of pie chart corresponds with population size).




selected for an interview through systematic random sampling. In total, interviews were conducted in 563 households with the head of household being the first approached; if not present, the spouse or a household member aged 15 years or older was asked to participate.

The questionnaire contained questions on basic demographic and socioeconomic characteristics of the respondent and the household. A set of questions related to awareness of, response to, and preparedness for the 2012 Indian Ocean earthquakes were also included. Questions regarding experience with the 2004 tsunami, social activities engaged in, and channels of information received were also asked. The final sample consisted of 557 households with valid responses to all questions used in the analysis. The data on basic demographic and education at the village-level was obtained from the 2010 Population and Housing Census, supplied in an aggregated form by the National Statistical Office, Thailand.

\section{Variables}

The empirical analysis explored determinants of disaster preparedness actions based on characteristics associated with preparedness behaviors as cited in previous literature. In particular, we investigated the relationships between formal education and disaster preparedness.

\section{Dependent variable}

Given the fact that Thailand's southern Andaman coast was on high alert because of the Indonesian and subsequent Phuket earthquakes during the period of the survey, the outcome of interest was whether people living in the high-risk areas were taking any measures to prepare for the earthquakes and the hazards that might follow. The dependent variable was taken from the question which asks: "Have you or your family taken any preparedness actions after the 11 April 2012 Indonesian earthquake?" Response categories were: (1) no preparation; (2) keeping close watch of the situation; (3) preparation of survival kits; (4) planning evacuation procedure and emergency plan with household members; (5) inspection of house structure; and (6) other preparations.

\section{Explanatory variables}

1) Education: Following the hypotheses that education could enhance awareness and preparedness for disasters, we measured the relationships between education and preparedness after the Indian Ocean earthquakes at three levels.

- Individual level - the highest level of education of the respondents divided into four categories: (1) no education and elementary; (2) lower secondary; (3) upper secondary; and (4) tertiary

- Household level - the number of household members with at least secondary education

- Village level - proportion of men and women with at least secondary education in the village
2) Disaster-related variables: We included disaster-related variables previously found to be associated with disaster preparedness (Mileti and Fitzpatrick 1992, Faupel and Styles 1993, Heller et al. 2005, Mishra and Suar 2007). These variables were measured at the individual level, including:

- Tsunami experience - coded 1 if the respondent was affected by the 2004 tsunami; 0 otherwise

- Participation in tsunami drills and disaster education code 1 if the respondent participated in tsunami drills and/or disaster education; 0 otherwise

- Number of information sources - a continuous variable measuring the number of sources of information where the respondents obtained the news about the 11 April 2012 earthquakes and tsunami warnings

\section{Control variables}

Control variables included individual, household, village demographic, and other relevant characteristics.

- Individual level - age, sex, occupation, marital status, years of residence in a house

- Household level - household income, number of usual residents, number of members aged 0-5 years, number of household members aged $\geq 60$ years, number of disabled members, whether household located on the coast

- Village level - village indicator, proportion of women, proportion of people aged $\geq 65$ years

All independent variables included in the multivariate analyses were tested for a potential problem of multicollinearity and no problem was detected.

\section{Statistical techniques}

To investigate the determinants of personal preparedness, we performed chi-square analysis comparing the number of preparedness activities undertaken by demographic and socioeconomic characteristics. In the case where the determinants were continuous variables, one-way analysis of variance (ANOVA) was performed to compare means of the relevant variables by number of preparedness activities.

Subsequently, positing that a person's disaster preparation outcome was likely to be a product of individual and household characteristics, as well as the characteristics of the village in which the person lives, we performed multivariate analysis to explore the influence of different factors on disaster preparedness actions at the same time.

Because the outcome variable (number of preparedness measures taken) was not normally distributed, ordinary least squares regression could not be used because the normality assumption would be violated. We then grouped the number of preparation activities into three ordinal categories: no 
preparation, one preparation measure, two or more preparation measures. Although ordered logistic regression is an appropriate method for an ordinal response variable, the model is only valid for the data that meet the proportional odds assumption, that is, the coefficients that describe the relationship between any two pairs of outcome groups are statistically the same. For our data, the likelihood-ratio test showed that the proportional odds assumption was violated (Wolfe and Gould 1998). Thus we decided to adopt the partial proportional odds model, which allows the coefficients that violate the proportional odds assumption to vary across logistic equations, i.e., to have different effects on the dependent variable (Peterson and Harrell 1990, Fullerton and $\mathrm{Xu}$ 2012).

The partial proportional odds model (PPOM) can be expressed as a generalized ordered logit model:

$$
\begin{gathered}
P\left(Y_{i}>j\right)=\mathrm{g}\left(\mathrm{X} \beta_{j}\right)=\frac{\exp \left(\propto_{j}+X_{i} \beta_{j}\right)}{1+\left[\exp \left(\propto_{j}+X_{i} \beta_{j}\right)\right]} \\
\text { with } j=1,2 \ldots, M-1
\end{gathered}
$$

where $M$ is the number of categories of the ordinal dependent variable ( 3 in our case) and $\beta_{j}$ is unique for each $j$ for the coefficients that the proportional odds assumption is violated otherwise $\beta_{j}=\beta$. For our analysis, $M=3$ thus the PPOM is equivalent to a series of binary logistic regressions where categories of the dependent variable are combined. The dependent variable is defined over an increasing number of preparation measures taken: $Y=1$ for no preparation, $Y=2$ for one preparation measure taken, and $Y=3$ for two or more preparation measures taken. In our case, $M=3$, then for $J=1$ category $Y 1$ is contrasted with $Y 2$ and $Y 3$ (logit 1); and for $J$ $=2$ the contrast is between $Y 1$ and $Y 2$ versus $Y 3$ (logit 2). This way each group is compared to groups with higher number of preparation measures.

All statistical analyses were carried out in the statistical software STATA, version 11 and the PPOM is estimated using gologit2, a user written program (Williams 2006).

\section{RESULTS}

Binary relationships between disaster preparedness and individual, household, and village characteristics

Table 1 describes demographic characteristics of the sample at the individual, household, and village levels. Binary relationships between these characteristics and the number of preparedness measures taken are also presented. As shown in Table 1, the number of preparedness actions carried out differs notably by age and occupation: $28.6 \%$ of individuals in the youngest age group, $34.7 \%$ of those in the oldest age group, and $44 \%$ of those engaged in agriculture did not take any preparedness actions. Disaster-related variables are significantly associated with disaster preparedness. Respondents who were affected by the 2004 tsunami and participated in evacuation drills and disaster education are more likely to be prepared and more likely to undertake more than just one preparedness measure. Individuals with higher number of sources of information on tsunami and earthquakes news are also more likely to be prepared.

Considering household characteristics, demographic composition in a household is related to disaster preparedness, whereby households with a higher number of members aged $\geq 60$ years (0.72) and a lower number of members with disability (0.02) are less likely to be prepared. Note that on the average the number of elderly and disabled household members is less than 1 in most households. Preparedness is significantly related with household location: only $14.3 \%$ of those living on the coast were not prepared as compared to $38.9 \%$ of those whose house located $\geq 1 \mathrm{~km}$ from the shore. With respect to village characteristics, respondents living in a village with higher proportion of women had lower rates of taking preparedness actions.

Regarding disaster preparedness and education, there is a weak relationship between individual education and the number of preparedness measures taken. Those with no education or with only elementary education were less likely to be prepared (29.4\%). Respondents with tertiary education were more likely to be prepared and to have taken more than one preparedness action $(41.2 \%)$. The average education level in a village is also highly correlated with disaster preparedness, with the respondents with higher number of preparation activities being more likely to live in a village with a higher proportion of men and women with at least secondary education.

\section{Disaster preparedness considering village effects}

In Table 2, we apply the partial proportional odds model (PPOM) to estimate the factors associated with disaster preparedness, taking into account the differences between villages. Models 1 and 2 include a village indicator variable to control for the possibility that disaster preparedness outcome can vary depending on the village in which one lives.

In Model 3, we explore the relationships between village demographic characteristics and disaster preparedness. Note that the village indicators are not included in Model 3 because the models with village indicators are equivalent to a fixed effects estimator where village-level covariates are treated as nuisances and cannot be estimated (Paul et al. 2010). We also exclude the two villages in our original sample where all respondents have taken preparedness actions (see Fig. 1). The analysis in Tables 2 and 3 thus include the sample of 544 subjects.

Our interpretation of the parameter estimates is as follows. The results can be interpreted in the same way as traditional ordered logit models, that is, the change in the log odds of the 
Table 1. Summary statistics of individual-, household-, and village-level characteristics and binary relationships between these characteristics and disaster preparedness.

\begin{tabular}{|c|c|c|c|c|c|}
\hline & No preparation & One preparation & $\begin{array}{l}\text { Two or more } \\
\text { preparations }\end{array}$ & $\mathrm{N}$ & Total \\
\hline \multicolumn{6}{|l|}{ Individual characteristics } \\
\hline \multicolumn{6}{|l|}{ Educational attainment+ } \\
\hline no \& elementary education & $29.4 \%$ & $43.4 \%$ & $27.2 \%$ & 371 & $66.6 \%$ \\
\hline lower secondary & $23.7 \%$ & $56.6 \%$ & $19.7 \%$ & 76 & $13.6 \%$ \\
\hline upper secondary & $23.7 \%$ & $40.7 \%$ & $35.6 \%$ & 59 & $10.6 \%$ \\
\hline tertiary & $17.6 \%$ & $41.2 \%$ & $41.2 \%$ & 51 & $9.2 \%$ \\
\hline \multicolumn{6}{|l|}{ Status in household } \\
\hline head of household & $28 \%$ & $44.9 \%$ & $27.1 \%$ & 336 & $60.3 \%$ \\
\hline not head of household & $25.3 \%$ & $44.3 \%$ & $30.3 \%$ & 221 & $39.7 \%$ \\
\hline Years of residence in household & $27.93(20.21)$ & $25.33(15.42)$ & $25.58(16.32)$ & 557 & 26.1(17.09) \\
\hline \multicolumn{6}{|l|}{ Sex } \\
\hline men & $27.9 \%$ & $47 \%$ & $25.1 \%$ & 251 & $45.1 \%$ \\
\hline women & $26.1 \%$ & $42.8 \%$ & $31 \%$ & 306 & $54.9 \%$ \\
\hline \multicolumn{6}{|l|}{$\mathrm{Age}^{* *}$} \\
\hline$<30$ years & $28.6 \%$ & $32.9 \%$ & $38.6 \%$ & 70 & $12.6 \%$ \\
\hline $30-39$ years & $20.8 \%$ & $50.9 \%$ & $28.3 \%$ & 106 & $19 \%$ \\
\hline 40 - 49 years & $25.2 \%$ & $53.3 \%$ & $21.5 \%$ & 135 & $24.2 \%$ \\
\hline $50-59$ years & $25.4 \%$ & $41 \%$ & $33.6 \%$ & 122 & $21.9 \%$ \\
\hline 60 years and over & $34.7 \%$ & $40.3 \%$ & $25 \%$ & 124 & $22.3 \%$ \\
\hline \multicolumn{6}{|l|}{ Marital status } \\
\hline divorced/separated/widowed & $24.1 \%$ & $51.9 \%$ & $24.1 \%$ & 79 & $14.2 \%$ \\
\hline married & $26.2 \%$ & $44.7 \%$ & $29.1 \%$ & 409 & $73.4 \%$ \\
\hline single & $34.8 \%$ & $36.2 \%$ & $29 \%$ & 69 & $12.4 \%$ \\
\hline \multicolumn{6}{|l|}{ Occupation** } \\
\hline fishery & $23.1 \%$ & $50 \%$ & $26.9 \%$ & 52 & $9.3 \%$ \\
\hline agriculture & $44 \%$ & $44 \%$ & $12 \%$ & 75 & $13.5 \%$ \\
\hline laborer & $27.6 \%$ & $37.9 \%$ & $34.5 \%$ & 87 & $15.6 \%$ \\
\hline general trade/own business & $24.2 \%$ & $44.8 \%$ & $30.9 \%$ & 194 & $34.8 \%$ \\
\hline private employee/civil servant & $13.9 \%$ & $55.6 \%$ & $30.6 \%$ & 36 & $6.5 \%$ \\
\hline economically inactive & $25.7 \%$ & $44.2 \%$ & $30.1 \%$ & 113 & $20.3 \%$ \\
\hline \multicolumn{6}{|l|}{ Experience of 2004 tsunami** } \\
\hline not affected & $40.7 \%$ & $38.9 \%$ & $20.4 \%$ & 216 & $38.8 \%$ \\
\hline affected & $18.2 \%$ & $48.4 \%$ & $33.4 \%$ & 341 & $61.2 \%$ \\
\hline \multicolumn{6}{|c|}{ Participated in evacuation drills and disaster education** } \\
\hline not participated & $38 \%$ & $40.7 \%$ & $21.4 \%$ & 332 & $59.6 \%$ \\
\hline participated & $10.7 \%$ & $50.7 \%$ & $38.7 \%$ & 225 & $40.4 \%$ \\
\hline Number of sources of information** & $2.41(1.02)$ & $2.94(1.44)$ & $3.2(1.48)$ & 557 & $2.87(1.38)$ \\
\hline \multicolumn{6}{|l|}{ Household characteristics } \\
\hline \multicolumn{6}{|c|}{ Number of members with at least secondary education } \\
\hline none & $29.3 \%$ & $43.8 \%$ & $26.9 \%$ & 283 & $50.8 \%$ \\
\hline one person & $23.8 \%$ & $46.4 \%$ & $29.8 \%$ & 168 & $30.2 \%$ \\
\hline two or more persons & $25.5 \%$ & $44.3 \%$ & $30.2 \%$ & 106 & $19 \%$ \\
\hline Number of persons in household & $3.98(2.21)$ & $3.73(1.95)$ & $3.96(1.80)$ & 557 & $3.87(1.98)$ \\
\hline Number of children aged $\leq 5$ years & $0.37(0.67)$ & $0.36(0.63)$ & $0.39(0.67)$ & 557 & $0.37(0.65)$ \\
\hline Number of members aged $\geq 60$ years** & $0.72(0.98)$ & $0.39(0.66)$ & $0.52(0.82)$ & 557 & $0.52(0.81)$ \\
\hline Number of members with disability** & $0.02(0.14)$ & $0.03(0.18)$ & $0.08(0.28)$ & 557 & $0.04(0.20)$ \\
\hline \multicolumn{6}{|l|}{ Household income } \\
\hline$<$ THB 10,000 & $27.8 \%$ & $46.5 \%$ & $25.8 \%$ & 198 & $35.5 \%$ \\
\hline THB $10,000-19,999$ & $26 \%$ & $46.2 \%$ & $27.8 \%$ & 223 & $40 \%$ \\
\hline THB 20,000 - 29,999 & $26.4 \%$ & $42.5 \%$ & $31 \%$ & 87 & $15.6 \%$ \\
\hline THB 30,000 and over & $28.6 \%$ & $34.7 \%$ & $36.7 \%$ & 49 & $8.8 \%$ \\
\hline \multicolumn{6}{|l|}{ House location** } \\
\hline house located on the coast & $14.3 \%$ & $50 \%$ & $35.7 \%$ & 70 & $12.6 \%$ \\
\hline house located $<1 \mathrm{~km}$ from the shore & $19.9 \%$ & $48.3 \%$ & $31.8 \%$ & 261 & $46.9 \%$ \\
\hline house located $\geq 1 \mathrm{k} \mathrm{m}$ from the shore & $38.9 \%$ & $38.9 \%$ & $22.1 \%$ & 226 & $40.6 \%$ \\
\hline
\end{tabular}


Village characteristics

Percentage of men with at least secondary education**

Percentage of women with at least secondary education**

Percentage of members aged 60 years and over
Percentage of women**

\begin{tabular}{rrrrr}
$20.39(6.21)$ & $23.19(6.22)$ & $24.65(7.63)$ & 557 & $22.85(6.83)$ \\
$24.9(6.61)$ & $30.39(6.59)$ & $31.23(6.43)$ & 557 & $29.15(7.04)$ \\
$5.67(2.41)$ & $5.52(1.79)$ & $5.24(1.74)$ & 557 & $5.48(1.97)$ \\
$46.14(2.79)$ & $45.13(2.32)$ & $44.4(2.17)$ & 557 & $45.19(2.50)$ \\
\hline
\end{tabular}

Note: Standard deviations are in parentheses. For categorical variables, chi-square tests were performed to test the relationship between that particular variable and disaster preparedness. For continuous variables, ANOVA was applied.

THB $=$ Thai baht

$* * \mathrm{p}<0.05$ response variable per unit change in the predictor. Tables 2 and 3 present the results in odds ratio $(\mathrm{OR})$, the exponential function of the regression coefficient $\left(\exp ^{\beta}\right)$. OR $>1$ indicates the higher odds of preparedness while OR $<1$ indicates the lower odds of preparedness. Unlike the ordered logit models, in the PPOM, multiple coefficients are estimated for each variable that violates the proportional odds assumption. Accordingly, for these variables, two different coefficients are listed. The first coefficient (not in bold) predicts responses for the first logit equation (Logit 1) whereas the second coefficient (in bold) predicts responses for the second logit equation (Logit 2). In Logit 1 the reference group is no preparation; while in Logit 2 the reference group is individuals who have not done any preparation or have taken only one preparedness measure. The percentage change in odds for each unit increase in the independent variable is calculated using the formula: $100\left(\exp ^{\beta}-1\right)$.

The model estimates in Table 2 are presented in a forward stepwise manner. Model 1 investigates the relationships between individual demographic characteristics including disaster-related variables and disaster preparedness. Individual education and marital status appear to be a key determinant of disaster preparedness. Generally speaking, higher levels of education are strongly associated with a higher number of disaster preparedness activities. Likewise, individuals who are married are more likely to be prepared. With respect to disaster-related variables, the experience of tsunami in 2004 and participation in evacuation drills and disaster education are not significantly associated with disaster preparedness, unlike what we found in the binary statistics. The number of sources of information is positively related to the number of preparedness actions taken. An increase in one source of information increases the odds of preparation by 1.35 times. Model 2 includes household characteristics. Household income has no significant relationship with disaster preparedness. Consistent with the binary statistics, the greater the number of household members aged $\geq 60$ years, the lower the likelihood of preparation, but this applies only to the first logit equation. Likewise, the greater the number of disabled members, the greater the odds of preparedness. We find a weak positive relationship between education of household members and the number of preparedness activities taken. Model 3 includes village characteristics. In this model, the coefficients for education of household members become statistically significant. It is also found that while $1 \%$ increase in the proportion of women in a village reduces the likelihood of preparation by $17 \%$, a $1 \%$ increase in the proportion of women with at least secondary education increases the odds of preparation by $11 \%$.

\section{Variation of determinants of disaster preparedness by individual education and previous tsunami experience}

It is also of interest to compare whether the effects of the determinants of disaster preparedness vary by individual education and tsunami experience. In Table 3 we estimate the PPOM models splitting the sample by: (1) individual education, defined as individuals with less than secondary education and individuals with at least secondary education; and by (2) individual tsunami experience, defined as individuals not affected by the 2004 tsunami and individuals affected by the 2004 tsunami. Splitting the sample by individual education, Table 3 shows that the predictors of the likelihood of preparation vary considerably by educational level. For respondents with low educational attainment, the main factors influencing disaster preparedness are the number of sources of information and some household demographic characteristics, i.e., the number of the elderly and disabled member. On the other hand, for individuals with higher education, it is evident that their likelihood of taking preparedness actions increases with tsunami experience, participation in evacuation drills, disaster education, and the number of sources of information received. For this group the number of household members with at least secondary education further increases the likelihood of preparation. The odds of undertaking preparatory activities significantly increase by 2.5 and 4.5 times for highly educated individuals living in a household with one, two, or more members with at least secondary education respectively.

Regarding the analysis that splits the sample by tsunami experience, Table 3 reports that for individuals not being affected by the 2004 tsunami, evidently education of the household members is a key driver for taking preparedness actions. For this group, the odds of preparedness for those living in a household with two or more members with at least secondary education is 6.6 times greater than those living in a household where none of the household members possess 
Table 2. Odds ratio estimated from partial proportion odds ordered logit models predicting disaster preparedness with village indicators and characteristics.

\begin{tabular}{|c|c|c|c|c|c|c|}
\hline & \multicolumn{2}{|c|}{ Model 1} & \multicolumn{2}{|c|}{ Model 2} & \multicolumn{2}{|c|}{ Model 3} \\
\hline & $\beta$ & s.e. & $\beta$ & s.e. & $\beta$ & s.e. \\
\hline \multicolumn{7}{|l|}{ Individual characteristics } \\
\hline \multicolumn{7}{|l|}{ Education (ref: no \& elementary) } \\
\hline lower secondary & 0.942 & $(0.254)$ & 0.976 & $(0.279)$ & 0.935 & $(0.266)$ \\
\hline upper secondary & $1.882 * *$ & $(0.584)$ & $1.749+$ & $(0.576)$ & 1.642 & $(0.534)$ \\
\hline tertiary & $2.327 * *$ & $(0.787)$ & $2.116^{* *}$ & $(0.786)$ & $1.985+$ & $(0.731)$ \\
\hline Head of household & 0.902 & $(0.204)$ & 0.886 & $(0.209)$ & 0.935 & $(0.218)$ \\
\hline Years of residence in household & 1.003 & $(0.006)$ & 1.005 & $(0.007)$ & 1.006 & $(0.007)$ \\
\hline Women & 1.361 & $(0.298)$ & 1.410 & $(0.317)$ & 1.349 & $(0.301)$ \\
\hline \multicolumn{7}{|l|}{ Age (ref: < 30 years) } \\
\hline \multirow[t]{2}{*}{30 - 39 years } & 0.784 & $(0.265)$ & 1.180 & $(0.496)$ & 1.189 & $(0.494)$ \\
\hline & & & $0.510+$ & $(0.199)$ & 0.533 & $(0.206)$ \\
\hline \multirow[t]{2}{*}{40 - 49 years } & 0.912 & $(0.351)$ & 0.937 & $(0.385)$ & 1.043 & $(0.419)$ \\
\hline & $0.436 * *$ & $(0.167)$ & $0.321 * *$ & $(0.131)$ & $0.351 * *$ & $(0.140)$ \\
\hline $50-59$ years & 0.925 & $(0.345)$ & 0.851 & $(0.333)$ & 0.915 & $(0.352)$ \\
\hline \multirow[t]{2}{*}{60 years and over } & 0.696 & $(0.291)$ & 1.539 & $(0.824)$ & 1.603 & $(0.841)$ \\
\hline & & & & & $0.400+$ & $(0.216)$ \\
\hline \multicolumn{7}{|l|}{ Marital status (ref: single) } \\
\hline divorced/separated/widowed & 1.088 & $(0.438)$ & 0.995 & $(0.427)$ & 1.102 & $(0.467)$ \\
\hline married & $1.890 * *$ & $(0.590)$ & $1.964 * *$ & $(0.648)$ & $1.918^{* *}$ & $(0.629)$ \\
\hline \multicolumn{7}{|l|}{ Occupation (ref: agriculture) } \\
\hline fishery & 0.586 & $(0.245)$ & 0.636 & $(0.278)$ & 0.696 & $(0.300)$ \\
\hline \multirow[t]{2}{*}{ laborer } & 1.094 & $(0.388)$ & 0.590 & $(0.244)$ & 0.734 & $(0.297)$ \\
\hline & & & 1.610 & $(0.645)$ & 1.840 & $(0.726)$ \\
\hline general trade/own business & 0.855 & $(0.270)$ & 0.841 & $(0.276)$ & 1.038 & $(0.333)$ \\
\hline private employee/civil servant & 1.088 & $(0.480)$ & 1.082 & $(0.501)$ & 1.344 & $(0.611)$ \\
\hline economically inactive & 1.232 & $(0.418)$ & 1.165 & $(0.411)$ & 1.307 & $(0.454)$ \\
\hline Affected by tsunami in 2004 & $1.450+$ & $(0.315)$ & 1.425 & $(0.325)$ & 1.172 & $(0.255)$ \\
\hline Participated in evacuation drills and disaster education & 1.465 & $(0.359)$ & 1.462 & $(0.370)$ & 1.340 & $(0.334)$ \\
\hline \multirow[t]{2}{*}{ Number of sources of information } & $1.354 * *$ & $(0.092)$ & $1.639 * *$ & $(0.180)$ & $1.647 * *$ & $(0.177)$ \\
\hline & & & & & $1.276 * *$ & $(0.100)$ \\
\hline \multicolumn{7}{|l|}{ Household characteristics } \\
\hline \multicolumn{7}{|c|}{ Number of members with at least secondary education (ref: none) } \\
\hline one person & & & 1.315 & $(0.289)$ & $1.511+$ & $(0.323)$ \\
\hline two or more persons & & & $1.665+$ & $(0.460)$ & $1.820 * *$ & $(0.499)$ \\
\hline \multicolumn{7}{|l|}{ Household income (ref: < THB 10,000) } \\
\hline THB $10,000-19,999$ & & & 0.959 & $(0.212)$ & 1.014 & $(0.218)$ \\
\hline THB 20,000 - 29,999 & & & 0.830 & $(0.248)$ & 0.857 & $(0.252)$ \\
\hline THB 30,000 and over & & & 0.939 & $(0.357)$ & 0.907 & $(0.341)$ \\
\hline Number of persons in household & & & 0.939 & $(0.060)$ & 0.929 & $(0.058)$ \\
\hline Number of children aged $\leq 5$ years & & & 0.910 & $(0.150)$ & 0.950 & $(0.156)$ \\
\hline \multirow[t]{2}{*}{ Number of members aged $\geq 60$ years } & & & $0.461 * *$ & $(0.086)$ & $0.507 * *$ & $(0.088)$ \\
\hline & & & $1.413+$ & $(0.270)$ & $1.445 * *$ & $(0.263)$ \\
\hline Number of members with disability & & & $3.805^{* *}$ & $(1.802)$ & $3.785^{* *}$ & $(1.746)$ \\
\hline \multicolumn{7}{|l|}{ House location (ref: house located on the coast) } \\
\hline house located $<1 \mathrm{~km}$ from the shore & & & 0.761 & $(0.216)$ & 0.737 & $(0.209)$ \\
\hline house located $\geq 1 \mathrm{~km}$ from the shore & & & 0.864 & $(0.293)$ & 0.747 & $(0.244)$ \\
\hline Village characteristics & & & & & & \\
\hline Percentage of men with at least secondary education & & & & & 1.024 & $(0.024)$ \\
\hline Percentage of women with at least secondary education & & & & & $1.114 * *$ & $(0.032)$ \\
\hline & & & & & 1.023 & $(0.031)$ \\
\hline Percentage of members aged 65 years and over & & & & & 0.978 & $(0.067)$ \\
\hline Percentage of women & & & & & $0.835^{* *}$ & $(0.052)$ \\
\hline Village indicators included & yes & & yes & & no & \\
\hline
\end{tabular}




\begin{tabular}{|c|c|c|c|c|c|c|}
\hline Constant_1 & 0.865 & $(0.582)$ & 1.011 & $(0.775)$ & 41.553 & (112.455) \\
\hline Constant_2 & $0.063 * *$ & $(0.043)$ & $0.100 * *$ & $(0.076)$ & 87.689 & (242.146) \\
\hline Log likelihood & -495.90 & & -470.00 & & -477.60 & \\
\hline DF & 29 & & 45 & & 42 & \\
\hline Pseudo $\mathrm{R}^{2}$ & 0.15 & & 0.20 & & 0.18 & \\
\hline $\mathrm{N}$ & 544 & & 544 & & 544 & \\
\hline
\end{tabular}

Note: Coefficients not in bold indicate the estimate under the proportional odds assumption whereas bold coefficients are variables that violate the proportional odds assumption. The coefficients not in bold are for the first logit equation contrasting no preparation versus one preparation and two preparations or higher. The bold coefficients are for the second logit equation contrast no preparation and one preparation versus two preparations or higher.

THB $=$ Thai baht

$* * \mathrm{p}<0.05,+\mathrm{p}<0.1$

secondary level education. In addition, individuals with lower secondary qualification also have a greater propensity for preparation compared to those with no education or only elementary qualification. Likewise, the likelihood of preparation significantly increases with the number of sources of information for this group. For individuals who were affected by the 2004 tsunami, the likelihood of being prepared is significantly associated with marital status and household characteristics. The odds of taking preparedness actions for the divorced/separated/widowed and the married are six and eight times greater than for single individuals. Although the number of the elderly in household (applied only to Logit 1) reduces the likelihood of preparation, the number of disabled members increases the propensity to carry out preparedness activities.

\section{DISCUSSION}

Our multivariate estimation shows that formal education is positively related to preparedness actions at the individual, household, and village levels. We find that the positive effect of individual and household-level education remain after controlling for household income. This suggests that education has an independent effect from income in increasing preparedness. Thus Hypothesis 1, which states that education increases disaster preparedness through improving income level, is not supported. Subsequently, there is weak evidence that education may increase cognitive ability and risk perception because it is found that being affected by the 2004 tsunami increases the likelihood of preparedness, but this applies only to those with tertiary education. This implies that the highly educated group managed to translate their previous disaster experience into preparedness actions. Hypothesis 2 thus is partially supported.

As predicted in Hypothesis 3, we also observe a strong interaction between individual educational attainment and informal education on disaster preparedness. Participating in evacuation drills and disaster education increases the likelihood of undertaking preparedness actions, but this applies only to the respondents with at least secondary education. It is plausible that highly educated individuals have better learning skills and are better in processing abstract thinking, e.g., in a hypothetical situation like a tsunami drill.

Apart from the effects of individual education, we find that education of household members enhances disaster preparedness, especially among the individuals who were not affected by the 2004 tsunami. Whereas disaster experience can increase disaster awareness and consequently preparedness action (Russell et al. 1995, Sattler et al. 2000, Horney et al. 2008, Tekeli-Yeşil et al. 2010), those who do not have such experience may have difficulty in perceiving the risk associated with a particular natural hazard. Our results nevertheless show that for those without previous tsunami experience, education of household members together with the number of information sources are key factors that drive disaster preparedness. Because information is processed through multiple stages, hearing the information, understanding it, and perceiving its relevance (Nigg 1982), education can shape the degree to which individuals accurately perceive and assess risks and make a decision to take on preparedness actions. In this sense, education may increase risk awareness without having to experience a natural disaster directly.

We also find that individual disaster preparedness differs by demographic and educational composition of the village. In general, the greater the proportion of the female population in the village, the lower the personal disaster preparedness. On the other hand, the greater proportion of women with at least secondary education, the higher the likelihood of taking preparedness actions. This raises a question of why gender and educational composition in a community could affect individual emergency preparedness behaviors. One explanation is that women are more likely to have denser social ties comprising a higher proportion of kin and neighbors than men (Moore 1990, Renzulli et al. 2000), so they might be more likely to exchange information and mutual assistance. However, women usually have fewer socioeconomic resources and less access to formal emergency planning organizations (Fothergill 1996). A community with a higher proportion of females in the population might have lower disaster preparedness because women have less access to 
Table 3. Odds ratio estimated from partial proportion odds ordered logit models predicting disaster preparedness with village indicators: samples split by respondents' level of education and experience of the 2004 tsunami.

\begin{tabular}{|c|c|c|c|c|c|c|c|c|}
\hline & \multicolumn{4}{|c|}{ Individual educational level } & \multicolumn{4}{|c|}{ Experience of 2004 tsunami } \\
\hline & \multicolumn{2}{|c|}{ Less than secondary } & \multicolumn{2}{|c|}{$\begin{array}{l}\text { Secondary } \\
\text { and over }\end{array}$} & \multicolumn{2}{|c|}{ Not affected } & \multicolumn{2}{|c|}{ Affected } \\
\hline & $\beta$ & s.e. & $\beta$ & s.e. & $\beta$ & s.e. & $\beta$ & s.e. \\
\hline \multicolumn{9}{|l|}{ Individual characteristics } \\
\hline \multicolumn{9}{|l|}{ Education (ref: no \& elementary) } \\
\hline lower secondary & na. & & na. & & $3.051 * *$ & $(1.730)$ & 0.728 & $(0.288)$ \\
\hline upper secondary & na. & & na. & & 2.084 & $(1.120)$ & 1.455 & $(0.669)$ \\
\hline tertiary & na. & & na. & & 1.680 & $(1.062)$ & $2.547+$ & $(1.304)$ \\
\hline Head of household & 0.841 & $(0.246)$ & 1.046 & $(0.492)$ & 1.195 & $(0.571)$ & $\begin{array}{l}1.272 \\
\mathbf{0 . 4 7 0} * *\end{array}$ & $\begin{array}{l}(0.528) \\
(\mathbf{0 . 1 6 9 )}\end{array}$ \\
\hline Years of residence in household & 1.005 & $(0.008)$ & 1.002 & $(0.016)$ & 1.011 & $(0.012)$ & 0.998 & $(0.011)$ \\
\hline Women & 1.452 & $(0.411)$ & 1.439 & $(0.616)$ & 1.179 & $(0.485)$ & $\begin{array}{l}0.951 \\
\mathbf{2 . 7 3 7} * *\end{array}$ & $\begin{array}{l}(0.388) \\
(\mathbf{0 . 9 4 7})\end{array}$ \\
\hline \multicolumn{9}{|l|}{ Age (ref: < 30 years) } \\
\hline $30-39$ years & $\begin{array}{l}0.743 \\
\mathbf{0 . 9 3 1}\end{array}$ & $\begin{array}{l}(0.465) \\
(\mathbf{0 . 5 9 3})\end{array}$ & 0.661 & $(0.342)$ & $\begin{array}{l}2.177 \\
\mathbf{0 . 3 2 3}\end{array}$ & $\begin{array}{l}(1.485) \\
(\mathbf{0 . 2 3 2})\end{array}$ & 0.541 & $(0.270)$ \\
\hline $40-49$ years & $0.317+$ & $(0.205)$ & 0.414 & $(0.258)$ & $\begin{array}{l}2.907 \\
\mathbf{0 . 0 6 8} * *\end{array}$ & $\begin{array}{l}(2.007) \\
(\mathbf{0 . 0 6 1 )}\end{array}$ & $0.362+$ & $(0.190)$ \\
\hline $50-59$ years & $\begin{array}{l}0.986 \\
\mathbf{1 . 9 6 0}\end{array}$ & $\begin{array}{l}(0.601) \\
(\mathbf{1 . 4 2 4})\end{array}$ & 0.765 & $(0.562)$ & 1.107 & $(0.813)$ & $\begin{array}{l}0.294^{* *} \\
\mathbf{0 . 9 1 9}\end{array}$ & $\begin{array}{l}(0.180) \\
(\mathbf{0 . 5 0 0 )}\end{array}$ \\
\hline 60 years and over & 0.618 & $(0.459)$ & $0.009 * *$ & $(0.015)$ & 1.222 & $(1.223)$ & 0.403 & $(0.265)$ \\
\hline \multicolumn{9}{|l|}{ Marital status (ref: single) } \\
\hline divorced/separated/widowed & 0.803 & $(0.500)$ & $17.624+$ & $(26.386)$ & 0.976 & $(0.726)$ & $6.106^{* *}$ & $(4.745)$ \\
\hline married & 1.611 & $(0.898)$ & $5.112 * *$ & $(3.026)$ & 1.494 & $(0.796)$ & $7.938 * *$ & $(4.596)$ \\
\hline \multicolumn{9}{|l|}{ Occupation (ref: agriculture) } \\
\hline fishery & 0.757 & $(0.390)$ & 0.254 & $(0.240)$ & 1.657 & $(1.793)$ & 0.525 & $(0.299)$ \\
\hline \multirow[t]{2}{*}{ laborer } & & & & & 0.479 & $(0.328)$ & 0.385 & $(0.242)$ \\
\hline & 1.189 & $(0.537)$ & 1.056 & $(0.860)$ & $3.567+$ & $(2.413)$ & 1.236 & $(0.732)$ \\
\hline general trade/own business & 0.923 & $(0.358)$ & 0.802 & $(0.554)$ & 1.195 & $(0.700)$ & 0.472 & $(0.220)$ \\
\hline private employee/civil servant & 1.184 & $(0.873)$ & 0.808 & $(0.622)$ & 0.888 & $(0.817)$ & 0.832 & $(0.523)$ \\
\hline economically inactive & 1.033 & $(0.420)$ & 2.468 & $(2.051)$ & 1.404 & $(0.818)$ & 0.736 & $(0.394)$ \\
\hline Affected by tsunami in 2004 & 1.301 & $(0.374)$ & $2.132+$ & $(0.916)$ & na. & & na. & \\
\hline $\begin{array}{l}\text { Participated in evacuation drills and disaster } \\
\text { education }\end{array}$ & 1.337 & $(0.418)$ & $2.774 * *$ & $(1.403)$ & 1.316 & $(0.692)$ & 1.495 & $(0.478)$ \\
\hline Number of sources of information & $1.351 * *$ & $(0.118)$ & $1.580^{* *}$ & $(0.234)$ & $2.238^{* *}$ & $(0.349)$ & 1.165 & $(0.110)$ \\
\hline \multicolumn{9}{|l|}{ Household characteristics } \\
\hline \multicolumn{9}{|c|}{ Number of members with at least secondary education (ref: none) } \\
\hline one person & 1.081 & $(0.298)$ & $2.482 * *$ & $(1.098)$ & $2.066+$ & $(0.862)$ & 0.923 & $(0.273)$ \\
\hline two or more persons & 1.263 & $(0.422)$ & $4.500 * *$ & $(2.667)$ & $6.579 * *$ & $(4.068)$ & 1.559 & $(0.580)$ \\
\hline \multicolumn{9}{|l|}{ Household income (ref: < THB 10,000) } \\
\hline THB $10,000-19,999$ & 0.970 & $(0.253)$ & 1.066 & $(0.539)$ & 1.705 & $(0.739)$ & 0.782 & $(0.228)$ \\
\hline THB 20,000 - 29,999 & 0.994 & $(0.381)$ & 0.721 & $(0.421)$ & 0.691 & $(0.381)$ & 0.769 & $(0.307)$ \\
\hline THB 30,000 and over & 0.961 & $(0.528)$ & 0.438 & $(0.310)$ & $0.165^{* *}$ & $(0.138)$ & 1.254 & $(0.640)$ \\
\hline Number of persons in household & 0.968 & $(0.076)$ & 0.870 & $(0.119)$ & $\begin{array}{l}0.818 \\
1.354 * *\end{array}$ & $\begin{array}{l}(0.115) \\
(\mathbf{0 . 2 0 5})\end{array}$ & $0.858+$ & $(0.074)$ \\
\hline Number of children aged $\leq 5$ years & 0.990 & $(0.204)$ & $\begin{array}{l}0.287 * * \\
\mathbf{1 . 0 4 2}\end{array}$ & $\begin{array}{l}(0.127) \\
(\mathbf{0 . 3 7 1})\end{array}$ & 0.998 & $(0.291)$ & 0.876 & $(0.191)$ \\
\hline Number of members aged $\geq 60$ years & $\begin{array}{l}0.497 * * \\
\mathbf{1 . 2 2 1}\end{array}$ & $\begin{array}{l}(0.097) \\
(\mathbf{0 . 2 6 3})\end{array}$ & 1.654 & $(0.763)$ & 0.831 & $(0.292)$ & $\begin{array}{l}0.575^{* *} \\
\mathbf{1 . 5 2 4 +}\end{array}$ & $\begin{array}{l}(0.125) \\
(\mathbf{0 . 3 4 2})\end{array}$ \\
\hline Number of members with disability & $4.009 * *$ & $(2.120)$ & 2.322 & $(3.082)$ & 3.243 & $(3.651)$ & $5.173 * *$ & $(3.162)$ \\
\hline $\begin{array}{l}\text { House location (ref: house located on the coast) } \\
\text { house located }<1 \mathrm{~km} \text { from the shore }\end{array}$ & 1.047 & $(0.377)$ & 0.533 & $(0.300)$ & $\begin{array}{l}1.511 \\
\mathbf{0 . 5 0 5}\end{array}$ & $\begin{array}{l}(1.122) \\
(\mathbf{0 . 3 6 2})\end{array}$ & 0.716 & $(0.243)$ \\
\hline
\end{tabular}




\begin{tabular}{|c|c|c|c|c|c|c|c|c|}
\hline house located $\geq 1 \mathrm{~km}$ from the shore & 1.067 & $(0.461)$ & 0.859 & $(0.572)$ & 1.062 & $(0.758)$ & 0.974 & $(0.414)$ \\
\hline Village indicators included & yes & & yes & & yes & & yes & \\
\hline Constant_1 & 1.459 & $(1.479)$ & 0.417 & $(0.573)$ & 0.233 & $(0.304)$ & $9.772 * *$ & $(11.069)$ \\
\hline Constant_2 & $0.089 * *$ & $(0.091)$ & $0.023^{* *}$ & $(0.031)$ & $0.009 * *$ & $(0.012)$ & 0.759 & $(0.806)$ \\
\hline Log likelihood & -318.10 & & -139.20 & & -157.20 & & -275.70 & \\
\hline DF & 39 & & 38 & & 45 & & 44 & \\
\hline Pseudo $\mathrm{R}^{2}$ & 0.18 & & 0.28 & & 0.31 & & 0.19 & \\
\hline $\mathrm{N}$ & 360 & & 184 & & 216 & & 328 & \\
\hline
\end{tabular}

Note: Coefficients not in bold indicate the estimate under the proportional odds assumption whereas bold coefficients are variables that violate the proportional odds assumption. The coefficients not in bold are for the first logit equation contrasting no preparation versus one preparation and two preparations or higher. The bold coefficients are for the second logit equation contrast no preparation and one preparation versus two preparations or higher.

THB = Thai baht

$* * \mathrm{p}<0.05,+\mathrm{p}<0.1$

information channels (Katungi et al. 2008) and consequently could not share useful information. However, living in a community with high proportion of highly educated women increases personal disaster preparedness because education can increase access to disaster-related information and socioeconomic resources. The disaster preparedness of other members in a community hence can benefit from such female social networks.

The finding that disaster preparedness increases with the level of education is consistent with other studies in Asia that focus on other types of disaster outcomes. For instance, earlier research has found that communities in Nepal with higher levels of education suffer fewer human and animal deaths because of floods and landslides (K.C. 2013). Likewise, highly educated individuals in Indonesia are reported to cope better with the post-tsunami phase of the disaster, especially over the long run (Frankenberg et al. 2013). These findings show that education can be an important resource to reduce vulnerability to environmental hazards in Asia.

Although in this paper we have provided evidence of the role of education in enhancing disaster preparedness and investigated how formal schooling and informal education interact with disaster experience, it is beyond the scope of this study to identify how formal education can increase preparedness activities through other factors, e.g., risk perception, not observed in this study. Preparedness actions are related to both the perceptions of risk and an individual's capacity to take protective action and responses (Slovic 2000). The perception of risk varies considerably with past disaster experience, as well as demographic and socioeconomic profiles. Educational differences in disaster preparedness might partly be due to how individuals with diverse levels of education perceive risk in different ways based on their cognitive ability. Likewise, formal education may translate into a better ability to understand disaster education. Further study, especially a qualitative one, is required to deepen our understanding of the role of formal education on disaster preparedness.
This current study is not without limitations. First, the study may suffer from a selection bias of the out-migration of individuals or households with certain characteristics from areas at risk to tsunami. In the case of Thailand, however, there is no evidence that a mass exodus of tsunami affected population occurred after the 2004 Indian Ocean tsunami (Naik et al. 2007). Hence, the selection problem seems to be minimal in our study. Second, there was a potential of respondents misreporting their preparedness actions. They might over-report their evacuation plan or preparedness kit due to a social desirability bias, with the respondents wanting to be viewed favorably by the interviewer, or feeling obliged to report that they had the plan or kit prepared in response to the earthquake. Likewise, there was also a possibility of underreporting disaster preparedness because of recall bias, although most of the interviews were carried out shortly after the earthquakes. Because the study does not have information on preparedness from other sources, the data presented here rely solely on the respondents' accounts and report behavior. Lastly, the data do not allow us to identify who actually initiated emergency preparedness actions in a household because the survey interviewed only one respondent per household. We thus control for whether the respondent is a head of household in the analysis as a proxy for decision making power. A future study should attempt to identify who actually implemented preparedness measures in a household to better understand how individual and household characteristics influence disaster preparedness.

\section{CONCLUSION}

In this study we provide evidence that education, measured at the individual, household, and village levels, has a significant relationship with disaster preparedness. We distinguish between the effects of formal schooling and disaster-related training on preparedness actions and find that disaster education is effective particularly in the context of participants who have high educational attainment. Formal education may enhance cognitive ability, information processing, and learning skills so individuals with higher education respond 
better in hard times, such as when the disaster strikes. Indeed, in the absence of past disaster experience, we find that households with highly educated members are better prepared for the disasters. There is also a spillover effect of education, possibly through communication and information exchange among village members as evidenced by the finding that living in a village with higher proportion of highly educated female members is positively associated with the number of preparedness activities undertaken at the individual and household level.

We show that disaster-related education can enhance personal preparedness, which is crucial in mitigating the disaster risks. However, the effectiveness of such education might be limited only to a subgroup of the population, such as highly educated individuals. Thus, policies that ensure universal access to formal education at least at the secondary level can be beneficial in reducing vulnerability and mitigating disaster impacts.

Responses to this article can be read online at:

http://www.ecologyandsociety.org/issues/responses. $\mathrm{php} / 6101$

\section{Acknowledgments:}

Funding for this work was made possible by an Advanced Grant of the European Research Council, "Forecasting Societies Adaptive Capacities to Climate Change" (grant agreement ERC-2008-AdG 230195-FutureSoc) and

Ratchadaphiseksomphot Endowment Fund of Chulalongkorn University for the project "Understanding Social Barriers to Coping with and Adapting to Extreme Climate Events" (Grant agreement number: RES560530150-CC). The authors wish to thank Rugsapong Sanitya for organizing and preparing the survey data and Thana-on Punkasem for her assistance in creating a map of Phang Nga.

\section{LITERATURE CITED}

Asfaw, A., and A. Admassie. 2004. The role of education on the adoption of chemical fertiliser under different socioeconomic environments in Ethiopia. Agricultural Economics 30:215-228.

Baker, E. J. 2011. Household preparedness for the aftermath of hurricanes in Florida. Applied Geography 31:46-52. http:// dx.doi.org/10.1016/j.apgeog.2010.05.002

Banerjee, M. M., and D. F. Gillespie. 1994. Strategy and organizational disaster preparedness. Disasters 18:344-354. http://dx.doi.org/10.1111/j.1467-7717.1994.tb00321.x

Basolo, V., L. J. Steinberg, R. J. Burby, J. Levine, A. M. Cruz, and C. Huang. 2009. The effects of confidence in government and information on perceived and actual preparedness for disasters. Environment and Behavior 41:338-364. http://dx. doi.org/10.1177/0013916508317222

Bourque, L. B., D. S. Mileti, M. Kano, and M. M. Wood. 2012. Who prepares for terrorism? Environment and Behavior 44:374-409. http://dx.doi.org/10.1177/0013916510390318

Bravo, M., M. Rubio-Stipec, G. J. Canino, M. A. Woodbury, and J. C. Ribera. 1990. The psychological sequelae of disaster stress prospectively and retrospectively evaluated. American Journal of Community Psychology 18:661-680. http://dx.doi. org/10.1007/BF00931236

British Broadcasting Corporation (BBC). 2012. Indian Ocean tsunami alert lifted after Aceh quake. BBC, UK. [online] URL: http://www.bbc.co.uk/news/world-asia-17675399

Burchi, F. 2010. Child nutrition in Mozambique in 2003: the role of mother's schooling and nutrition knowledge. Economics and Human Biology 8:331-345. http://dx.doi. org/10.1016/j.ehb.2010.05.010

Chula International Communication Center (CICC).2012. Likelihood of earthquakes in Thailand. CICC, Bangkok, Thailand. [online] URL: http://www.cicc.chula.ac.th/ en/2012-04-26-04-31-26/203-likelihood-of-earthquakes-in-thailand. html

Dash, N., and H. Gladwin. 2007. Evacuation decision making and behavioral responses: individual and household. Natural Hazards Review 8:69-77. http://dx.doi.org/10.1061/(ASCE) $\underline{1527-6988(2007) 8: 3(69)}$

Edwards, M. L. 1993. Social location and self-protective behavior: implications for earthquake preparedness. International Journal of Mass Emergencies and Disasters 11:293-303.

Eisenman, D. P., C. Wold, J. Fielding, A. Long, C. Setodji, S. Hickey, and L. Gelberg. 2006. Differences in individual-level terrorism preparedness in Los Angeles County. American Journal of Preventive Medicine 30:1-6. http://dx.doi. org/10.1016/j.amepre.2005.09.001

Faupel, C. E., S. P. Kelly, and T. Petee. 1992. The impact of disaster education on household preparedness for Hurricane Hugo. International Journal of Mass Emergencies and Disasters 10:5-24.

Faupel, C. E., and S. P. Styles. 1993. Disaster education, household preparedness, and stress responses following Hurricane Hugo. Environment and Behavior 25:228-249. http://dx.doi.org/10.1177/0013916593252004

Ferdinand, I., G. O'Brien, P. O'Keefe, and J. Jayawickrama. 2012. The double bind of poverty and community disaster risk reduction: a case study from the Caribbean. International Journal of Disaster Risk Reduction 2:84-94. http://dx.doi. org/10.1016/j.ijdrr.2012.09.003 
Food and Agriculture Organization of the United Nations (FAO). 2005. Report of Joint FAO/MOAC Detailed Technical Damages and Needs Assessment Mission in Fisheries and Agriculture Sectors in Tsunami Affected Six Provinces in Thailand. FAO, Bangkok, Thailand.

Fothergill, A. 1996. Gender, risk, and disaster. International Journal of Mass Emergencies and Disasters 14:33-56.

Frankenberg, E., B. Sikoki, C. Sumantri, W. Suriastini, and D. Thomas. 2013. Education, vulnerability, and resilience after a natural disaster. Ecology and Society 18(2): 16. http:// dx.doi.org/10.5751/ES-05377-180216

Fullerton, A. S., and J. Xu. 2012. The proportional odds with partial proportionality constraints model for ordinal response variables. Social Science Research 41:182-198. http://dx.doi. org/10.1016/j.ssresearch.2011.09.003

Glewwe, P. 1999. Why does mother's schooling raise child health in developing countries? Evidence from Morocco. Journal of Human Resources 3:124-159 http://dx.doi. org/10.2307/146305

Heller, K., D. B. Alexander, M. Gatz, B. G. Knight, and T. Rose. 2005. Social and personal factors as predictors of earthquake preparation: the role of support provision, network discussion, negative affect, age, and education. Journal of Applied Social Psychology 35:399-422. http://dx.doi. org/10.1111/j.1559-1816.2005.tb02127.x

Horney, J., C. Snider, S. Malone, L. Gammons, and S. Ramsey. 2008. Factors associated with hurricane preparedness: results of a pre-hurricane assessment. Journal of Disaster Research 3:143-149.

Howell, S. E., and D. E. Bonner. 2005. Citizen hurricane evacuation behavior in Southeastern Louisiana: a twelve parish survey. University of New Orleans, New Orleans, Louisiana, USA.

Jackson, E. L. 1981. Response to earthquake hazard: the West Coast of North America. Environment and Behavior 13:387-416. http://dx.doi.org/10.1177/0013916581134001

Jamison, D. T., and P. R. Moock. 1984. Farmer education and farm efficiency in Nepal: the role of schooling, extension services, and cognitive skills. World Development 12:67-86. http://dx.doi.org/10.1016/0305-750X(84)90036-6

Katungi, E., S. Edmeades, and M. Smale. 2008. Gender, social capital and information exchange in rural Uganda. Journal of International Development 20:35-52. http://dx.doi.org/10.1002/ jid.1426

K. C., S. 2013. Community vulnerability to floods and landslides in Nepal. Ecology and Society 18(1): 8.

Kim, Y.-C., and J. Kang. 2010. Communication, neighbourhood belonging and household hurricane preparedness. Disasters 34:470-488. http://dx.doi.org/10.1111/ j.1467-7717.2009.01138.x

Kohn, S., J. L. Eaton, S. Feroz, A. A. Bainbridge, J. Hoolachan, and D. J. Barnett. 2012. Personal disaster preparedness: an integrative review of the literature. Disaster Medicine and Public Health Preparedness 6:217-231. http://dx.doi. org/10.1001/dmp.2012.47

Lehman, D. R., and S. E. Taylor. 1987. Date with an earthquake: coping with a probable, unpredictable disaster. Personality and Social Psychology Bulletin 13:546-555. http://dx.doi.org/10.1177/0146167287134011

Lindell, M. K., and R. W. Perry. 2000. Household adjustment to earthquake hazard: a review of research. Environment and Behavior 32:461-501. http://dx.doi.org/10.1177/00139160021972621

Liu, S., L. E. Quenemoen, J. Malilay, E. Noji, T. Sinks, and J. Mendlein. 1996. Assessment of a severe-weather warning system and disaster preparedness, Calhoun County, Alabama, 1994. American Journal of Public Health 86:87-89. http://dx. doi.org/10.2105/AJPH.86.1.87

Menard, L. A., R. O. Slater, and J. Flaitz. 2011. Disaster preparedness and educational attainment. Journal of Emergency Management 9:45-52.

Miceli, R., I. Sotgiu, and M. Settanni. 2008. Disaster preparedness and perception of flood risk: a study in an alpine valley in Italy. Journal of Environmental Psychology 28:164-173. http://dx.doi.org/10.1016/j.jenvp.2007.10.006

Mileti, D. S., and C. Fitzpatrick. 1992. The causal sequence of risk communication in the Parkfield earthquake prediction experiment. Risk Analysis 12:393-400. http://dx.doi. org/10.1111/j.1539-6924.1992.tb00691.x

Mishra, S., S. Mazumdar, and D. Suar. 2010. Place attachment and flood preparedness. Journal of Environmental Psychology 30:187-197. http://dx.doi.org/10.1016/j.jenvp.2009.11.005

Mishra, S., and D. Suar. 2005. Age, family and income influencing disaster preparedness behaviour. Psychological Studies 50:322-326.

Mishra, S., and D. Suar. 2007. Do lessons people learn determine disaster cognition and preparedness? Psychology \& Developing Societies 19:143-159. http://dx.doi. org/10.1177/097133360701900201

Moore, G. 1990. Structural determinants of men's and women's personal networks. American Sociological Review 55:726-735. http://dx.doi.org/10.2307/2095868

Murphy, S. T., M. Cody, L. B. Frank, D. Glik, and A. Ang. 2009. Predictors of emergency preparedness and compliance. Disaster Medicine and Public Health Preparedness. 
Naik, A., E. Stigter, and F. Laczko. 2007. Migration, development and natural disasters: insights from the Indian Ocean tsunami. IOM Migration Research Series, International Organization for Migration, Geneva, Switzerland.

Nidhiprabha, B. 2010. Thailand. Pages 171-224 in S. Jayasuriya and P. McCawley, editors. The Asian tsunami: aid and reconstruction after a disaster. The Asian Development Bank Institute and Edward Elgar Publishing, Cheltenham, UK.

Nigg, J. M. 1982. Communication under conditions of uncertainty: understanding earthquake forecasting. Journal of Communication 32:27-36. http://dx.doi.org/10.1111/j.1460-2466.1982. tb00474.x

Norris, F. H., T. Smith, and K. Kaniasty. 1999. Revisiting the experience-behavior hypothesis: the effects of Hurricane Hugo on hazard preparedness and other self-protective acts. Basic and Applied Social Psychology 21:37-47.

Page, L., J. Rubin, R. Amlôt, J. Simpson, and S. Wessely. 2008. Are Londoners prepared for an emergency? A longitudinal study following the London bombings. Biosecurity and Bioterrorism 6:309-319. http://dx.doi. org/10.1089/bsp.2008.0043

Paul, C., C. Claire, S. Fiona, and V. Anna. 2010. The choice between fixed and random effects models: some considerations for educational research. Department of Economics, University of Bristol, Bristol, UK.

Peterson, B., and F. E. Harrell, Jr. 1990. Partial proportional odds models for ordinal response variables. Applied Statistics 39:205-217. http://dx.doi.org/10.2307/2347760

Pollitz, F. F., R. S. Stein, V. Sevilgen, and R. Bürgmann. 2012. The 11 April 2012 east Indian Ocean earthquake triggered large aftershocks worldwide. Nature 490:250-253. http://dx. doi.org/10.1038/nature11504

Rachmalia, U. Hatthakit, and A. Chaowalit. 2011. Tsunami preparedness of people living in affected and non-affected areas: a comparative study in coastal area in Aceh, Indonesia. Australasian Emergency Nursing Journal 14:17-25. http://dx. doi.org/10.1016/j.aenj.2010.10.006

Ramirez, M., and C. Peek-Asa. 2005. Epidemiology of traumatic injuries from earthquakes. Epidemiologic Reviews 27:47-55. http://dx.doi.org/10.1093/epirev/mxi005

Reininger, B. M., M. H. Rahbar, M. Lee, Z. Chen, S. R. Alam, J. Pope, and B. Adams. 2013. Social capital and disaster preparedness among low income Mexican Americans in a disaster prone area. Social Science and Medicine 83:50-60. http://dx.doi.org/10.1016/j.socscimed.2013.01.037

Renzulli, L. A., H. Aldrich, and J. Moody. 2000. Family matters: gender, networks, and entrepreneurial outcomes. Social Forces 79:523-546. http://dx.doi.org/10.1093/sf/79.2.523
Rogers, E. M. 1995. Diffusion of innovations. Fourth edition. Free Press, New York, New York, USA.

Römer, H., P. Willroth, G. Kaiser, A. T. Vafeidis, R. Ludwig, H. Sterr, and J. Revilla Diez. 2012. Potential of remote sensing techniques for tsunami hazard and vulnerability analysis - a case study from Phang-Nga province, Thailand. Natural Hazards and Earth System Sciences 12:2103-2126. http://dx. doi.org/10.5194/nhess-12-2103-2012

Russell, L. A., J. D. Goltz, and L. B. Bourque. 1995. Preparedness and hazard mitigation actions before and after two earthquakes. Environment and Behavior 27:744-770. http://dx.doi.org/10.1177/0013916595276002

Sattler, D. N., C. F. Kaiser, and J. B. Hittner. 2000. Disaster preparedness: relationships among prior experience, personal characteristics, and distress. Journal of Applied Social Psychology 30:1396-1420. http://dx.doi.org/10.1111/ j.1559-1816.2000.tb02527.x

Selby, D., and F. Kagawa. 2012. Disaster risk reduction in school curricula: case studies from thirty countries. United Nations Educational, Scientific and Cultural Organization and United Nations Children Fund, Geneva, Switzerland.

Siegel, J. M., K. I. Shoaf, A. A. Afifi, and L. B. Bourque. 2003. Surviving two disasters: does reaction to the first predict response to the second? Environment and Behavior 35:637-654. http://dx.doi.org/10.1177/0013916503254754

Slovic, P. 2000. The perception of risk. Earthscan, London, UK.

Spittal, M. J., J. McClure, R. J. Siegert, and F. H. Walkey. 2008. Predictors of two types of earthquake preparation: survival activities and mitigation activities. Environment and Behavior 40:798-817. http://dx.doi.org/10.1177/0013916507309864

Tanaka, K. 2005. The impact of disaster education on public preparation and mitigation for earthquakes: a cross-country comparison between Fukui, Japan and the San Francisco Bay Area, California, USA. Applied Geography 25:201-225. http://dx.doi.org/10.1016/j.apgeog.2005.07.001

Tekeli-Yeşil, S., N. Dedeoğlu, M. Tanner, C. BraunFahrlaender, and B. Obrist. 2010. Individual preparedness and mitigation actions for a predicted earthquake in Istanbul. Disasters 34:910-930. http://dx.doi.org/10.1111/ j.1467-7717.2010.01175.x

Thanawood, C., C. Yongchalermchai, and O. Densrisereekul. 2006. Effects of the December 2004 tsunami and disaster management in southern Thailand. Science of Tsunami Hazards 24:206-217.

Thomas, D., J. Strauss, and M.-H. Henriques. 1991. How does mother's education affect child height? Journal of Human Resources 26:183-211 http://dx.doi.org/10.2307/145920 
Tierney, K. J., M. K. Lindell, and R. W. Perry. 2001. Facing hazards and disasters: understanding human dimensions. Joseph Henry Press, Washington, D.C., USA.

Turner, R. H., J. M. Nigg, and D. H. Paz. 1986. Waiting for disasters: earthquake watch in California. University of California Press, Berkeley, California, USA.

United Nations International Strategy for Disaster Reduction (UNISDR). 2007. Hyogo Framework for Action 2005-2015: building the resilience of nations and communities to disasters. UNISDR, Geneva, Switzerland.

U.S. Geological Survey (USGS). 2012. Magnitude 8.6 - Off the West coast of Northern Sumatra. USGS, Reston, Virginia, USA. [online] URL: http://earthquake.usgs.gov/earthquakes/ eqinthenews/2012/usc000905e/

Williams, R. 2006. Generalized ordered logit/partial proportional odds models for ordinal dependent variables. Stata Journal 6:58-82.

Wolfe, R., and W. Gould. 1998. An approximate likelihoodratio test for ordinal response models. Stata Technical Bulletin 